\title{
EFICIÊNCIA DE NINFAS E ADULTOS DE APHIS GOSSYPII GLOV. NA TRANSMISSÃO DO VÍRUS DO MOSAICO DAS NERVURAS DO ALGODOEIRO(1)
}

\author{
MARCOS DONISETI MICHELOTTO ${ }^{(2,4)}$; ANTONIOCARLOS BUSOLI ${ }^{(3)}$
}

\begin{abstract}
RESUMO
O objetivo deste trabalho foi avaliar a eficiência de transmissão do vírus do mosaico das nervuras, por ninfas e adultos de Aphis gossypii Glov., em duas cultivares de algodoeiro e registrar a evolução dos sintomas da doença. O trabalho foi realizado em casa de vegetação do Departamento de Fitossanidade da FCAV/UNESP, em Jaboticabal (SP). Ninfas e adultos ápteros criados em plantas infectadas da cultivar CNPTA ITA 90 foram transferidos para as plantas de algodoeiro das cultivares Coodetec 402 e CNPA ITA 90, com dois pares de folhas verdadeiras, onde permaneceram por 96 e 48 horas respectivamente. Para verificar a evolução da doença nas plantas, os sintomas foram avaliados até 60 dias após o confinamento dos afídeos, baseando-se numa escala de notas visuais. Os sintomas da doença foram inicialmente observados 25 dias após a inoculação pelos afídeos e se intensificaram com o desenvolvimento das plantas. A transmissão do vírus foi realizada mais eficientemente pelos adultos ápteros, do que pelas ninfas.
\end{abstract}

Palavras chave: Gossypium hirsutum, afídeo, vetor.

\section{ABSTRACT \\ EFFICIENCY OF NYMPHS AND ADULTS OF APHIS GOSSYPII GLOV. TO TRANSMIT COTTON VEIN MOSAIC VIRUS}

The objective of this work was to assess the efficiency of Aphis gossypii Glov. to transmit cotton vein mosaic virus and to register the evolution of the symptoms of disease. The work was accomplished in greenhouse of the Departament of Fitossanidade of FCAV/Unesp, at Jaboticabal, São Paulo State. Individual nymphs and wingless adult aphidis reared on infected 'CNPA ITA 90' cotton plants, were confined for 96 and 48 hours, respectively on cotton plants (cultivar CNPA ITA 90 and Coodetec 402) with two trues leaves. The evolution of the disease in the plants was recorded up to 60 days after the inoculation by the aphids appraising the symptoms using a visual scale of grades. The symptoms of the disease was first observed 25 days after the inoculation by the aphids and intensified during the plant development. Wingless adult aphids were more efficient than nymphs in the transmission of the virus.

Key words: Gossypium hirsutum, aphid, vector.

( $\left.{ }^{1}\right)$ Recebido para publicação em 28 de junho de 2002 e aceito em 21 de fevereiro de 2003.

$\left({ }^{2}\right)$ Mestre em Entomologia Agrícola, Faculdade de Ciências Agrárias e Veterinárias/UNESP, Via de Acesso Prof. Paulo Donato Castellane, s/no, 14884-900, Jaboticabal (SP). E-mail: mmichelotto@zipmail.com.br .

$\left(^{3}\right)$ Departamento de Fitossanidade, FCAV/UNESP. E-mail: acbusoli@fcav.unesp.br .

$\left({ }^{4}\right)$ Bolsista CAPES. 


\section{Introdução}

A introdução de genótipos de outros países como, Estados Unidos e Austrália, que prometiam diversas vantagens em relação às cultivares nacionais, como maior rendimento no descaroçamento, maior resistência de fibra, maior produtividade e melhor adaptação à colheita mecanizada, trouxe também problemas devido à alta suscetibilidade a viroses, como o vírus do vermelhão e o vírus do mosaico das nervuras, que não ocorriam no Brasil desde a década de 60, em vista da utilização de genótipos nacionais resistentes (FREIRE, 1999).

O mosaico das nervuras é atualmente uma das principais doenças do algodoeiro do cerrado brasileiro, devido à grande utilização de variedades suscetíveis como CNPA ITA 90 e Deltapine Acala 90 (CiA e FuZATto, 1999). Em alguns municípios de Minas Gerais e Goiás, as perdas de produtividade com essa doença chegaram a $1.500 \mathrm{~kg} \mathrm{ha}^{-1}$ de algodão em caroço (FreIrE, 1999). Os sintomas do mosaico das nervuras consistem na rugosidade e curvatura dos bordos foliares para baixo, principalmente nas folhas mais novas, clareamento das nervuras, formando mosaico, seguido de escurecimento das folhas mais velhas, encurtamento dos internódios, reduzindo, assim, o porte da planta. A estirpe ribeirão bonito provoca sintomas mais acentuados, reduzindo drasticamente o desenvolvimento das plantas (COSTA e Carvalho, 1962; Costa et al., 1997).

$\mathrm{O}$ vírus causador dessa doença não foi ainda isolado em sua forma pura e identificado. No entanto, sabe-se que sua transmissão é realizada pelo afídeo Aphis gossypii Glover, 1877, sendo essa transmissão do tipo persistente (Costa et al., 1997). Segundo os autores, outros afídeos, como Myzus persicae (Sulzer, 1776), Aphis rumicis Linnaeus, 1758, Aphis coreopsidis (Thomas, 1878) e Macrosiphum euphorbiae (Thomas, 1878) foram avaliados quanto à transmissibilidade do vírus e os resultados foram negativos.

A. gossypii é considerado praga inicial de algodoeiro, causa danos diretos pela sucção contínua da seiva, prejudicando as brotações novas e provocando a redução da produtividade e qualidade do algodão (Vendramim e NaKano, 1981). Entretanto, os danos indiretos causados pela transmissão de vírus, constituem o principal problema em cultivares suscetíveis ao vírus do mosaico-das-nervuras.

O objetivo deste trabalho foi avaliar a eficiência de transmissão de um isolado do vírus do mosaico das nervuras por ninfas e adultos de A. gossypii em duas cultivares de algodoeiro (Coodetec 402 e CNPA ITA 90) e registrar a evolução dos sintomas da doença, em condições controladas de casa de vegetação.

\section{Material e Métodos}

O experimento foi realizado em casa de vegetação, no Departamento de Fitossanidade da Faculdade de Ciências Agrárias e Veterinárias da UNESP, em Jaboticabal, Estado de São Paulo, Brasil.

Criação dos afídeos virulíferos - duas plantas da cultivar CNPA ITA 90, originárias de um plantio comercial de Campo Verde (MT), com características do mosaico das nervuras, foram mantidas em vasos de polietileno de 5 litros e isoladas por meio de gaiolas de estrutura metálica revestida por uma tela de "voil" $(60 \mathrm{~cm}$ de diâmetro x $120 \mathrm{~cm}$ de altura). Nessas plantas foram colocados exemplares de $A$. gossypii oriundos de algodoeiros da região de Jaboticabal, para que se alimentassem e se reproduzissem.

Instalação e desenvolvimento do experimento foram colocadas três sementes de algodoeiro em recipientes de polietileno de $500 \mathrm{~mL}$ contendo uma mistura de solo, vermiculita e esterco (2:2:1) da cultivar CNPA ITA 90, considerada altamente suscetível ao vírus do mosaico das nervuras por CIA e Fuzatto (1999). O mesmo procedimento foi utilizado para a cultivar Coodetec 402, considerada moderadamente resistente ao vírus (PenNA et al. 2001). Após a germinação das plantas, efetuou-se um desbaste, mantendo-se apenas uma planta por recipiente, sendo utilizadas 90 plantas de cada cultivar.

Quando as plantas apresentavam dois pares de folhas verdadeiras bem desenvolvidas, transferiu-se para cada planta, com o auxílio de um pincel, uma ninfa $\left(3 .^{\circ}\right.$ a $4 .^{\circ}$ estádio) ou um adulto áptero virulífero da criação.

Os afídeos permaneceram nas folhas, confinados em pequenas gaiolas formadas por um cilindro de plástico incolor de $4 \mathrm{~cm}$ de diâmetro e $1 \mathrm{~cm}$ de altura, com a extremidade superior fechada com "voil" e a outra fixada à folha por uma presilha de metal. Foi individualizada uma ninfa ou adulto áptero do afídeo por gaiola e por planta, os quais permaneceram confinados por um período de acesso à inoculação (PAI) de 96 e 48 horas respectivamente.

Avaliou-se o número de plantas que apresentaram os sintomas da doença, aos 30 e 60 dias após o PAI, calculando-se as respectivas porcentagens de plantas infectadas. Para verificar a evolução dos sintomas da virose, observaram-se os sintomas aos 20, 30, 40, 50 e 60 dias após o PAI, com base em uma escala de notas visuais, adaptada de Drck (1979) e FuzATto et al. (1997), em que as plantas recebem notas: 1 (planta sadia ou sem sintoma); 2 (uma ou duas 
folhas novas apresentando início de rugosidade e encurvamento), 3 (mesmo sintoma anterior e encurvamento das folhas mais velhas) e 4 (plantas com todas ou a maioria das folhas mostrando sintomas, nanismo das folhas novas e encurtamento dos internódios). Para as notas visuais, os tratamentos correspondem à combinação dos fatores cultivar, estágio do afídeo e dias após o PAI, com 45 plantas (repetições) cada um.

Análise estatística - os dados relacionados às notas atribuídas às plantas foram submetidos à análise de variância, em esquema fatorial, sendo as médias comparadas pelo teste de Tukey, a $5 \%$ de probabilidade.

\section{Resultados e Discussão}

O período de incubação e desenvolvimento dos sintomas exteriores do isolado do vírus do mosaico das nervuras foi inicialmente observado aos 25 dias após o PAI e continuaram a aparecer até os 40 dias, tanto nas plantas onde o vírus foi transmitido pelas ninfas, quanto pelos adultos ápteros, porém em proporções diferentes. Costa e Forster (1938) observaram um período de incubação para esse vírus de 26 a 69 dias, quando transmitido através de enxertias de plantas. CAUQuil e VAISSAYRe (1971), em experimento realizado com um vírus que ocorre em plantas de algodoeiro na
África, verificaram que os sintomas apareceram, em média, 18 dias após a inoculação dos afídeos. Os mesmos autores notaram que os diferentes estágios do afídeo (alados, ápteros e ninfas no fim de seu desenvolvimento) foram capazes de transmitir o vírus.

De acordo com Muñiz e Peña-Martínez (1992), diversos fatores podem influenciar no desenvolvimento da infecção viral, os intrínsecos (espécie, estágio e variedade da planta hospedeira; espécie/estirpe do vírus; espécie, estágio e origem do vetor, etc.) e os extrínsecos (condições climatológicas, práticas culturais, fatores que favorecem ou impedem a proliferação dos alados, etc.).

Trinta dias após o PAI, $15,6 \%$ e 17,8\% das plantas das cultivares Coodetec 402 e CNPA ITA 90, respectivamente, apresentaram os sintomas da doença causados pela transmissão do vírus pelas ninfas de A. gossypii. Entretanto, quando a transmissão foi realizada pelos afídeos adultos, 35,6\% (Coodetec 402) e $60,0 \%$ (CNPA ITA 90) das plantas apresentaram os sintomas (Figura 1).

Decorridos 60 dias, $77,8 \%$ das plantas de ambas as cultivares apresentaram os sintomas da doença quando infectados pelas ninfas. Quando a transmissão foi realizada pelos adultos, $86,7 \%$ e 95,6\% das plantas das cultivares Coodetec 402 e CNPA ITA 90, respectivamente, apresentaram os sintomas (Figura 1).

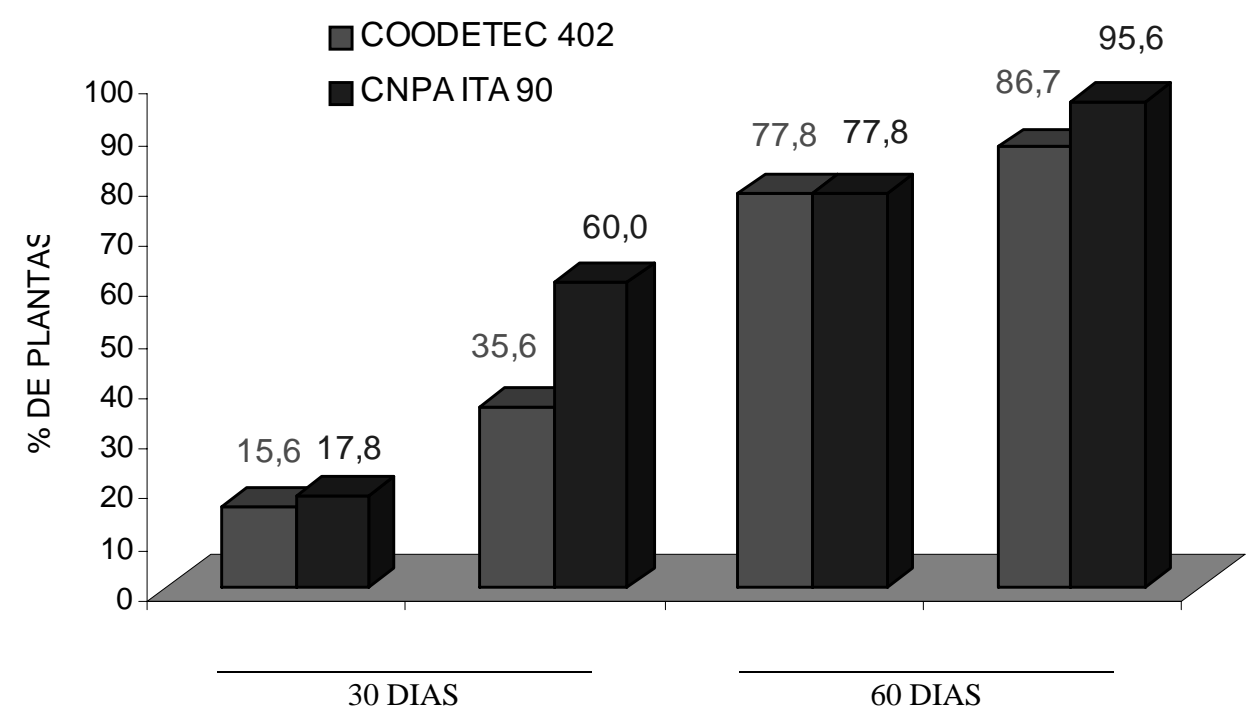

Figura 1. Porcentagem de plantas de algodoeiro com sintomas do vírus do mosaico dasnervuras aos 30 e 60 dias após o PAI dos afídeos virulíferos em plantas de duas cultivares de algodoeiro. Jaboticabal (SP), 2001. 
Como o mosaico das nervuras do algodoeiro vem sendo considerado como um Luteovirus, é interessante mencionar GiLl (1970) e ZHOU e Rochow (1984) os quais observaram que as ninfas de Schizaphis graminum (RONDANI, 1852) foram mais eficientes que os adultos na transmissão de um isolado do vírus do nanismo-amarelo da cevada (Luteovirus).

Observou-se o efeito dos fatores cultivar, estágio do afídeo e dias após o PAI nas notas visuais atribuídas às plantas de algodoeiro com sintomas do isolado do vírus do mosaico das nervuras (Quadro 1). As plantas da cultivar CNPA ITA 90 foram significativamente mais sensíveis ao vírus que as da Coodetec 402, com notas visuais médias de 2,09 $\pm 0,05$ e 1,94 \pm 0,05 respectivamente. Fortuna (2001) observou que, em condições de campo, as plantas da cultivar CNPA ITA 90 são mais suscetíveis ao vírus que as plantas da Coodetec 402.

Quadro 1. Análise de variância para as notas visuais dos sintomas do vírus do mosaico das nervuras em plantas de duas cultivares de algodoeiro após o PAI de $A$. gossypii. Jaboticabal (SP), 2001

\begin{tabular}{lc}
\hline Cultivar & Notas \\
\hline Coodetec 402 & $1,94 \pm 0,05 \mathrm{~b}$ \\
CNPA ITA 90 & $2,09 \pm 0,05 \mathrm{a}$ \\
Teste de F & $11,02^{* *}$ \\
DMS & 0,09 \\
\hline Estágio do afídeo & Notas \\
\hline Ninfa & $1,83 \pm 0,05 \mathrm{~b}$ \\
Adulto & $2,20 \pm 0,05 \mathrm{a}$ \\
Teste de F & $66,83^{* *}$ \\
DMS & 0,09 \\
\hline Dias após PAI & Notas ${ }^{1}$ \\
\hline 20 & 1,00 \\
30 & 1,37 \\
40 & 2,07 \\
50 & 2,46 \\
60 & 3,17 \\
Teste de F & $296,91^{* *}$ \\
DMS & 0,19 \\
\hline Teste de F Interação & Notas ${ }^{1}$ \\
\hline Cultivar x estágio afídeo & $29,17^{* *}$ \\
Estágio afídeo x dias após PAI & $1,16 \mathrm{~ns}$ \\
\hline
\end{tabular}

Médias seguidas de mesma letra na coluna não diferem significativamente entre si pelo teste de Tukey $(p>0,05)$.

**significativo a $1 \%$ de probabilidade.
Com relação aos estágios de $A$. gossypii, os adultos ápteros foram mais eficientes na transmissão do vírus $(2,20 \pm 0,05)$ que as ninfas $(1,83 \pm 0,05)$. Verificou-se aumento na severidade dos sintomas, com o decorrer do tempo até 60 dias após o PAI (Quadro 1). Houve também aumento do número de plantas demonstrando os sintomas do vírus com o desenvolvimento das plantas. A interação entre cultivar $x$ estágio do afídeo e estágio do afídeo $\mathrm{x}$ dias após o PAI foi significativa (Quadro 1). Os adultos foram mais eficientes na transmissão que as ninfas em ambas as cultivares (Quadro 2).

Quadro 2. Desdobramento da interação cultivar x estágio do afídeo para as notas visuais atribuídas às plantas de algodoeiro com sintomas do vírus do mosaico das nervuras. Jaboticabal (SP), 2001

\begin{tabular}{lccr}
\hline \multirow{2}{*}{ Cultivar } & \multicolumn{2}{c}{ Estágio do afídeo } & \\
\cline { 2 - 3 } & Ninfa & Adulto & Média \\
\hline Coodetec 402 & $\begin{array}{c}1,88 \pm 0,07 \mathrm{bA} \\
(\mathrm{n}=225)\end{array}$ & $\begin{array}{c}2,00 \pm 0,07 \mathrm{aB} \\
(\mathrm{n}=225)\end{array}$ & $\begin{array}{r}1,94 \pm 0,05 \\
(\mathrm{n}=450)\end{array}$ \\
\hline CNPA ITA 90 & $1,78 \pm 0,06 \mathrm{bA}$ & $2,39 \pm 0,08$ aA & $2,09 \pm 0,05$ \\
& $(\mathrm{n}=225)$ & $(\mathrm{n}=225)$ & $(\mathrm{n}=450)$ \\
\hline Média & $1,83 \pm 0,05$ & $2,20 \pm 0,05$ & $2,02 \pm 0,04$ \\
& $(\mathrm{n}=450)$ & $(\mathrm{n}=450)$ & $(\mathrm{n}=900)$ \\
\hline
\end{tabular}

Médias seguidas de mesma letra minúscula na linha e maiúscula na coluna não diferem significativamente entre si pelo teste de Tukey a $5 \%$ de probabilidade.

$\mathrm{n}=$ número de repetições.

\section{Conclusões}

1. Os sintomas do vírus do mosaico das nervuras podem ser visualizados a partir dos 25 dias após o período de acesso à inoculação dos afídeos, e continuam a aparecer por mais 15 dias.

2. Adultos ápteros de A. gossypii são mais eficientes que ninfas na transmissão do vírus.

3. As plantas da cultivar CNPA ITA 90 apresentaram maior sensibilidade ao vírus do mosaico das nervuras, do que as plantas da cultivar Coodetec 402.

\section{Referências Bibliográficas}

CAUQUIL, J.; VAISSAYRE, M. La maladie bleue du cotonier en Afrique: transmission de cotonnier à cotonnier par Aphis gossypii Glover. Coton et Fibres Tropicales, Paris, v.26, p.463-466, 1971. 
CIA, E.; FUZATTO, M.G. Manejo das doenças na cultura do algodão. In: CIA, E.; FREIRE, E.C.; SANTOS, W.J. (Eds.). Cultura do algodoeiro. Piracicaba: Potafós, 1999. p.121-131.

COSTA, A.S.; CARVALHO, A.M.B. Moléstias de vírus do algodoeiro. Bragantia, Campinas, v.21, p.45-62, 1962.

COSTA, A.S.; FORSTER, S. Nota preliminar sobre uma nova moléstia de vírus do algodoeiro: mosaico das nervuras. Revista de Agricultura, Piracicaba, v.13, p.187-191, 1938.

COSTA, A.S.; JULIATTI, F.C.; RUANO, O. Algodão (Gossypium hirsutum L.): doenças causadas por vírus. In: VALE, F.X.R. DO; ZAMBOLIM, L. (Eds.). Controle de Doenças de Plantas: grandes culturas. Viçosa, 1997. p.571-582.

DYCK, J.M. La maladie bleue du cotonier au Tchad. Coton et Fibres Tropicales, Paris, v.34, p.229-238, 1979.

FORTUNA, P.A. Competição de genótipos de algodoeiro em Primavera do Leste - MT. In: CONGRESSO BRASILEIRO DE ALGODÃO, 3., Campo Grande, 2001. Resumos... Campo Grande, 2001. p.153-154.

FREIRE, E.C. Doença azul tem solução. Cultivar, Pelotas, v.1, p.64-65, 1999.

FUZATTO, M.G.; CHIAVEGATO, E.J.; CIA, E. ET AL. Qualidade da fibra e da semente em plantas de algodoeiro afetadas pelo "murchamento avermelhado". Bragantia, Campinas, v.56, n.1, p.1-8, 1997.
GILL, C.C. Aphid nymphs transmit an isolate of barley yellow dwarf virus more efficiently than to adults. Phytopathology, Saint Paul, v.60, p.1747-1752, 1970.

MUÑIZ, R.B.; PEÑA-MARTÍNEZ, R. Afidos transmisores de virus fitopatogenos. In: URIAS, C.M.; RODRIGUEZ, M.R.; ALEJANDRE, A.T. Afidos como vectores de virus en Mexico. México: Centro de Fitopatologia, p.76-90, 1992. (Apostila)

PENNA, J.C.V.; MESQUITA, D.; FREIRE, E.C.; BELOT, J.L.; LANDIVAR, J.; LANZA, M.A.; FUZATTO, M.; AGUIAR, P.A. DE; CANCI, P.C. Sugestão de cultivares. In: CONGRESSO BRASILEIRO DE ALGODÃO, 3., 2001. Resumos de palestras... Campo Grande, 2001. p.140-145.

VENDRAMIM, J.D.; NAKANO, O. Aspectos biológicos de Aphis gossypii Glover, 1877 (Homoptera: Aphididae) em algodoeiro. Anais da Sociedade Entomológica do Brasil, Londrina, v.10, n.2, p.163-173, 1981.

ZHOU, G.; ROCHOW, W.F. Differences among five stages of Schizaphis graminum in transmission of a barley yellow dwarf luteovirus. Phytopathology, Saint Paul, v.74, p.1450-1453, 1984. 